\title{
Influence of Small Vessel Disease and Microstructural Integrity on Neurocognitive Functioning in Older Individuals: The DANTE Study Leiden
}

(D).E.F. Moonen, (D).C. Foster-Dingley, (D)A.A. van den Berg-Huijsmans, (DW. de Ruijter, (D)A.J.M. de Craen, (D). van der Grond, and (D).C. van der Mast

\section{ABSTRACT}

BACKGROUND AND PURPOSE: Small vessel disease is a major cause of neurocognitive dysfunction in the elderly. Small vessel disease may manifest as white matter hyperintensities, lacunar infarcts, cerebral microbleeds, and atrophy, all of which are visible on conventional MR imaging or as microstructural changes determined by diffusion tensor imaging. This study investigated whether microstructural integrity is associated with neurocognitive dysfunction in older individuals, irrespective of the conventional features of small vessel disease.

MATERIALS AND METHODS: The study included 195 participants (75 years of age or older) who underwent conventional 3T MR imaging with DTI to assess fractional anisotropy, mean diffusivity, axial diffusivity, and radial diffusivity. Cognitive tests were administered to assess cognitive domains, and the Geriatric Depression Scale-15 and Apathy Scale of Starkstein were used to assess symptoms of depression and apathy, respectively. The association between DTI measures and neurocognitive function was analyzed by using linear regression models.

RESULTS: In gray matter, a lower fractional anisotropy and higher mean diffusivity, axial diffusivity, and radial diffusivity were associated with worse executive function, psychomotor speed, and overall cognition and, in white matter, also with memory. Findings were independent of white matter hyperintensities, lacunar infarcts, and cerebral microbleeds. However, after additional adjustment for normalized brain volume, only lower fractional anisotropy in white and gray matter and higher gray matter radial diffusivity remained associated with executive functioning. DTI measures were not associated with scores on the Geriatric Depression Scale-15 or the Apathy Scale of Starkstein.

CONCLUSIONS: Microstructural integrity was associated with cognitive but not psychological dysfunction. Associations were independent of the conventional features of small vessel disease but attenuated after adjusting for brain volume.

ABBREVIATIONS: $A D=$ axial diffusivity; $G D S=$ Geriatric Depression Scale; $F A=$ fractional anisotropy $M D=$ mean diffusivity; $R D=$ radial diffusivity; $S V D=s m a l l$ vessel disease; $\mathrm{WMH}=$ white matter hyperintensity

$T^{T}$ he occurrence of small vessel disease (SVD), seen on conventional MR imaging as white matter hyperintensities (WMHs), lacunar infarcts, cerebral microbleeds, and brain atrophy, ${ }^{1}$ increases with advancing age. ${ }^{2}$ SVD is a major cause of cognitive ${ }^{3}$ and possibly psychological dysfunction. ${ }^{4}$ Nevertheless, the rela-

Received December 23, 2015; accepted after revision July 20, 2016.

From the Departments of Psychiatry (J.E.F.M., J.C.F.-D., R.C.v.d.M.), Radiology (A.A.v.d.B.-H., J.v.d.G.), Public Health and Primary Care (W.d.R.), and Gerontology and Geriatrics (A.J.M.d.C.), Leiden University Medical Center, Leiden, the Netherlands; and Department of Psychiatry (R.C.v.d.M.), Collaborative Antwerp Psychiatric Research Institute, University of Antwerp, Antwerp, Belgium.

J.E.F. Moonen and J.C. Foster-Dingley contributed equally.

The authors take full responsibility for the integrity of the data and analyses.

This study was supported by a grant from the Netherlands Organization for Health Research and Development (ZonMW) and Program Priority Medicines for the Elderly (No. 40-41600-98-9014).

The funding organization played no role in the design, conduct, or analysis of the study. tionship between these overt signs of SVD and cognitive and psychological dysfunction is modest, and interindividual variability is high. It is suggested that these visible lesions represent only the tip of the iceberg and that SVD may also cause more subtle and diffuse microstructural changes in the brain. Microstructural integrity can be determined with diffusion tensor imaging, which measures the diffusion of cerebral water molecules. Diffusion changes have been observed not only in lesions visible on standard MR imaging but also in the surrounding normalappearing brain tissue. ${ }^{5-7}$ The pathologic processes underlying changes in DTI measures include axonal degeneration and

\footnotetext{
Please address correspondence to Justine E.F. Moonen, MD, Department of Psychiatry, Leiden University Medical Center, PO Box 10392, 2300 WB, Leiden, the Netherlands; e-mail: j.e.f.moonen@lumc.nl

- Indicates open access to non-subscribers at www.ajnr.org

三 Indicates article with supplemental on-line tables.

http://dx.doi.org/10.3174/ajnr.A4934
} 
ischemic demyelination, ${ }^{7,8}$ which may lead to disruption of white matter tracts that connect brain regions involved in cognitive functions.

DTI measures of WM microstructural integrity may have additional value in explaining the variance in cognitive function beyond conventional MR imaging features of SVD. ${ }^{9}$ It has also been shown that microstructural integrity is an independent predictor of cognitive function beyond other features of SVD. Crosssectional studies in older individuals (mean age, 60-70 years) found that diffusion signal abnormality in WMHs, and particularly in normal-appearing white matter, was associated with cognitive dysfunction, irrespective of WMHs, lacunar infarcts, or brain volume. ${ }^{10-12}$ A longitudinal study in older individuals (mean age, 74 years) demonstrated that diffusion signal abnormalities in normal-appearing gray or white brain tissue, rather than in WMHs, predicted faster cognitive decline 3 years later, regardless of conventional SVD features. ${ }^{13}$ Furthermore, a crosssectional study (mean age, 69 years) found that compared with controls, older individuals with psychological dysfunction had diffusion signal abnormalities, even after the exclusion of WMHs from the DTI measurements. ${ }^{14}$

Currently, no data are available for determining the role of microstructural integrity as an independent predictor of neurocognitive function in the oldest elderly individuals, in whom overt features of SVD and, in particular, atrophy are more prevalent. Therefore, this cross-sectional study investigated whether microstructural integrity is independently associated with cognitive and psychological dysfunction in an older population (mean age, 81 years) beyond other features of SVD.

\section{MATERIALS AND METHODS Participants}

Participants for this cross-sectional study were included from the MR imaging substudy of the Discontinuation of Antihypertensive Treatment in Elderly People on Cognitive Functioning (DANTE) Study Leiden. ${ }^{15}$ Between June 2011 and August 2013, community-dwelling persons were included when they were 75 years of age or older, had a Mini Mental State Examination score between 21 and 27, were on antihypertensive medication, and had a current systolic blood pressure of $\leq 160 \mathrm{~mm} \mathrm{Hg}$. Excluded from the present study were participants with a clinical diagnosis of dementia, current angina pectoris, cardiac arrhythmia, heart failure, myocardial infarction, or a coronary reperfusion procedure $\leq 3$ years ago and a history of stroke or transient ischemic attack. A detailed description of the procedures used has been published previously. ${ }^{15}$

The Medical Ethical Committee of the Leiden University Medical Center approved the study, and written informed consent was obtained from all participants.

A total of 236 participants underwent MR imaging of the brain, of whom 16 were excluded due to incidental MR imaging findings (cortical infarcts, $n=8$; aneurysms, $n=2$; normal pressure hydrocephalus, $n=2$; meningioma, $n=1$; cavernoma, $n=$ 2 ; internal carotid artery occlusion, $n=1$ ). After an additional 25 were excluded due to DTI of insufficient quality, 195 participants were available for the present analyses.

\section{Data Acquisition}

Demographic and Clinical Characteristics. Demographic characteristics were assessed at baseline by using a standardized interview, and blood pressure was measured. ${ }^{15}$ General practitioners used structured questionnaires to obtain medical history and medication use.

MR Imaging Acquisition and Processing. All MR images were acquired on a whole-body Achieva MR imaging system operating at a field strength of 3T (Philips Healthcare, Best, the Netherlands), equipped with a 32-channel head coil. DTI was acquired with $\mathrm{TR} / \mathrm{TE}=9592 / 56 \mathrm{~ms}$, flip angle $=90^{\circ}, \mathrm{FOV}=220 \times 220 \times 128$ $\mathrm{mm}$, matrix size $=112 \times 110$, voxel dimension $=2 \mathrm{~mm}$ (isotropic), 64 sections, 32 measurement directions, $b=1000$. MR images were analyzed with the FMRIB Software Library, Version 5.0.1. (FSL (http://www.fmrib.ox.ac.uk/fsl). With the Diffusion Toolbox in FMRIB (http://fsl.fmrib.ox.ac.uk/fsl/fslwiki/FDT), individual fractional anisotropy (FA), mean diffusivity (MD), axial diffusivity $(\mathrm{AD})$, and radial diffusivity $(\mathrm{RD})$ images were created. ${ }^{16}$ Using the FMRIB Linear Image Registration Tool (FLIRT; http://www.fmrib.ox.ac.uk/) as a non-diffusion-weighted reference volume, we correlated original images for the effects of head movement and eddy currents in the gradient coils. A diffusion tensor model was fitted to the corrected images to create individual FA, MD, AD, and RD images. For global quantification of brain tissue $\mathrm{FA}, \mathrm{MD}, \mathrm{AD}$, and $\mathrm{RD}$ in white or gray brain tissue (which included WMH and other features of SVD), we skullstripped, ${ }^{17}$ segmented, ${ }^{18}$ and aligned 3D T1 images into the Montreal Neurological Institute 152 standard space by using FLIRT. Lower FA and higher $\mathrm{MD}, \mathrm{AD}$, and $\mathrm{RD}$ indicated poorer microstructural integrity.

Microbleeds were assessed by using $\mathrm{T} 2^{\star}$-weighted MR imaging $\left(\mathrm{TR} / \mathrm{TE}=45 / 31 \mathrm{~ms}\right.$, flip angle $=13^{\circ}, \mathrm{FOV}=250 \times 175 \times 112$ $\mathrm{mm}$, voxel dimension $=0.8 \mathrm{~mm}$, isotropic) and were defined as focal areas of signal void (on T2-MR imaging), which increased in size on $\mathrm{T} 2{ }^{*}$-weighted images (blooming effect) compared with the corresponding T2-weighted images $(\mathrm{TR} / \mathrm{TE}=4200 / 80 \mathrm{~ms}$, flip angle $=90^{\circ}, \mathrm{FOV}=224 \times 180 \times 144 \mathrm{~mm}$, matrix size $=$ $448 \times 320$, 40 sections, $3.6 \mathrm{~mm}$ thick). Symmetric hypointensities in the basal ganglia, likely representing nonhemorrhagic iron deposits, were disregarded. MR imaging acquisition; image processing; and analysis of WMH volume, brain volume, and lacunar infarcts have been described previously. ${ }^{19,20}$

\section{Cognitive and Psychological Function}

Global cognitive function was assessed with the Mini-Mental State Examination. Scores range from 0 to 30 points with higher scores indicating better performance. ${ }^{21}$ A battery of cognitive tests was administered from which cognitive domain compound scores were calculated. ${ }^{15}$ Executive function was assessed with the interference score of the abbreviated Stroop Color and Word Test $^{22}$ and by the difference between the time to complete the Trail-Making Test A and B. ${ }^{23}$ Memory was measured by using the immediate (3 trials) and delayed recall (1 trial) on the 15 -Word Verbal Learning Test and the Visual Association Test. ${ }^{24}$ Psychomotor speed was evaluated with the Letter Digit Substitution Test. ${ }^{25}$ These 6 tests were combined in the overall cognition com- 
pound score. The Geriatric Depression Scale (GDS)- $15^{26}$ was used to measure symptoms of depression (range, $0-15$ points, with higher scores indicating more symptoms), and the Apathy Scale of Starkstein, ${ }^{27}$ to measure symptoms of apathy (range, $0-42$ points, with higher scores indicating more symptoms).

\section{Statistical Analysis}

Characteristics of the participants are presented as mean $\pm \mathrm{SD}$, median (interquartile range), or as number (percentage), where appropriate. Education was dichotomized at primary education (6 years of schooling).

The distribution of WMH volume was skewed, which required transformation by a natural logarithm. Linear models were used in which DTI measures in white and gray matter (standardized $\mathrm{FA}, \mathrm{MD}, \mathrm{AD}$, and $\mathrm{RD}$ ) were entered as independent variables; and standardized cognitive domain scores or GDS-15 and Apathy Scale of Starkstein scores were entered as dependent variables. In model 1, these analyses were adjusted for age, sex, and education; model 2 included these same variables plus the number of lacunar infarcts and number of microbleeds and WMH volume; and in model 3, normalized brain volume was added.

The $F$ test was used to compare the fit (the $\mathrm{R}^{2}$; explained variance) of the different models. Voxelwise statistical analyses of the FA, MD, RD, and AD data were performed by using Tract-Based Spatial Statistics (TBSS; http://fsl.fmrib.ox.ac.uk/fsl/fslwiki/ TBSS), ${ }^{28}$ part of FSL. TBSS projects the FA data of all subjects onto a mean FA tract skeleton, before applying voxelwise cross-subject statistics.

Exploratory local DTI analyses were performed in the hippocampus, ${ }^{29,30}$ thalamus, ${ }^{31}$ putamen, ${ }^{20,32,33}$ and pre- and postcentral gyrus, ${ }^{31,33}$ because previous studies associated these areas with cognitive dysfunction. To explore the associations between DTI measures in white and gray matter and the features of SVD, we adjusted linear or logistic regression models for age and sex.

The SPSS software for Windows (Version 20.0.0.1; IBM, Armonk, New York) was used for statistical analyses. A P value $<.05$ was considered statistically significant.

\section{RESULTS}

\section{Demographic and Clinical Characteristics}

The Table presents the characteristics of the study population; the mean age was $80.7 \pm 4.1$ years, and $41.5 \%$ were men.

\section{DTI Measures and SVD}

In white matter, the $\mathrm{FA}, \mathrm{MD}, \mathrm{AD}$, and $\mathrm{RD}$ were all related to WMHs, lacunar infarcts, cerebral microbleeds, and normalized brain volume (all $P<.01$ ) (On-line Table 1 ). In gray matter, a higher FA was associated with a lower volume of WMH and fewer lacunar infarcts. In addition, in gray matter, higher $\mathrm{MD}, \mathrm{AD}$, and $\mathrm{RD}$ were associated with the presence of lacunar infarcts and microbleeds and, most strongly, with a lower normalized brain volume.

\section{DTI Measures and Cognitive and Psychological Function}

On-line Table 2 presents the associations between DTI measures in white matter and cognitive and psychological function. In model $1, \mathrm{MD}, \mathrm{AD}$, and $\mathrm{RD}$ in white matter were associated with

\section{Characteristics}

\section{Demographic and clinical}

Age (yr)

Male

Education ( $>6 \mathrm{yr}$ )

Current smoking

Diabetes mellitus

Cardiovascular disease ${ }^{b}$

Systolic blood pressure $(\mathrm{mm} \mathrm{Hg})$

Diastolic blood pressure $(\mathrm{mm} \mathrm{Hg})$

Cerebrovascular pathology and brain volumes

WMH volume $(\mathrm{mL})$

Lacunar infarcts present ${ }^{c}$

Cerebral microbleeds present

Brain volume total $(\mathrm{mL})$

Gray matter volume $(\mathrm{mL})$

White matter volume $(\mathrm{mL})$

Microstructural integrity in white and gray matter

Fractional anisotropy

White matter

Gray matter

Mean diffusivity $\left(\times 10^{-3} \mathrm{~mm}^{2} / \mathrm{s}\right)$

White matter

Gray matter

Axial diffusivity $\left(\times 10^{-3} \mathrm{~mm}^{2} / \mathrm{s}\right)$

White matter

Gray matter

Radial diffusivity $\left(\times 10^{-3} \mathrm{~mm}^{2} / \mathrm{s}\right)$

White matter

Gray matter

Cognitive and psychological measures

Mini-Mental State Examination

Executive $^{\mathrm{d}}$

$\Delta$ Trail-Making Test (sec)

Stroop interference score (sec)

Memory

15-Word Verbal Learning Test (words remembered)

Immediate-recall score

Delayed-recall score

Visual Association Test (pictures remembered)

Psychomotor speed

Letter Digit Substitution Test (digits coded)

Geriatric Depression Scale ${ }^{d}$

Apathy Scale of Starkstein ${ }^{d}$

${ }^{a}$ Data are presented as mean $\pm S D$, median (interquartile range), or as number (percentage) where appropriate.

${ }^{\mathrm{b}}$ Comprises myocardial infarction or a coronary intervention procedure $\geq 3$ years ago or peripheral artery disease.

${ }^{c}$ Missing for $n=4$ participants.

${ }^{\mathrm{d}}$ Higher scores indicate worse functioning.

${ }^{e} \Delta$ Trail-Making Test denotes difference between Trail-Making Test-B and TrailMaking Test-A.

worse executive function, memory, psychomotor speed, and overall cognition (all, $P<.05$ ). FA was associated with executive function and overall cognition. To assess the impact of diabetes mellitus and hypertension on our findings, we added these covariates separately to model 1 ; however, the results remained unchanged (data not shown). In model 2, additional adjustment for conventional features of SVD yielded similar effect estimates. In model 3, after further adjustment for brain volume, all these associations strongly attenuated, with only the association between 
FA in white matter and executive functioning remaining. Results for DTI measures in gray matter (On-line Table 3) followed a pattern similar to that of white matter, with the exception of the lack of any association with memory. After adjustment for normalized brain volume, only FA and RD in gray matter remained associated with executive functioning.

To assess the individual contribution of each covariate to overall cognitive functioning, we present the standardized $\beta$ coefficients for each variable in the fully adjusted model for 1 DTI measure (FA in white matter) in On-line Table 4. The largest effect estimates were found for education and normalized brain volume. Model 3 fit significantly better $(F$ test $<0.05)$ than model 2 for executive function, psychomotor speed, and overall cognition as indicated by footnote $c$ in On-line Tables 2 and 3 .

TBSS showed no associations between microstructural integrity and cognitive and psychological functioning. On-line Table 5 shows several associations between DTI measures in local brain regions and various cognitive domains. In both white and gray matter, global or local DTI measures were not associated with scores on the GDS-15 or the Apathy Scale of Starkstein.

\section{DISCUSSION}

This study shows that in older individuals with mild cognitive deficits, DTI abnormalities in the gray matter were associated with worse executive function, psychomotor speed, and overall cognition, whereas DTI abnormalities in white matter were, in addition, associated with memory. These relationships were independent of WMHs, lacunar infarcts, or cerebral microbleeds, but strongly attenuated after adjusting for brain volume.

In contrast to other studies, ${ }^{34,35}$ no global or local associations between microstructural integrity and symptoms of depression or apathy were found. Also, in contrast to our findings, a 3-year follow-up study in older individuals (mean age, 74 years) showed that DTI abnormalities in normal-appearing brain tissue predicted worse executive function, memory, and psychomotor speed, independent of WMHs, lacunar infarcts, and total brain volume. ${ }^{13}$ In addition, a large cross-sectional study in older individuals (mean age, 67 years) showed that diffusion signal abnormalities were associated with several cognitive domains irrespective of brain volume and other conventional features of SVD. ${ }^{12} \mathrm{~A}$ possible explanation for the differences between these latter study findings and ours is that we used different cognitive tests to assess cognitive function and included older participants, all of whom were using antihypertensive medication. In addition, adjusting for brain volume in populations with different ages (and a different prevalence for brain atrophy) is likely to yield different results.

The present study shows that most of the associations between DTI measures and cognitive dysfunction attenuated after adjusting for brain volume. It is possible that the observed associations were, at least in part, mediated by atrophy. In support of this hypothesis, a longitudinal study reported that midlife white matter diffusion signal abnormalities predicted white matter atrophy. ${ }^{36}$

However, several DTI measures in global and local brain regions were associated with cognitive functioning, irrespective of brain volume and overt features of SVD. FA in white and gray matter and $\mathrm{RD}$ in gray matter remained associated with executive functioning. Furthermore, $\mathrm{FA}$ in the putamen and $\mathrm{MD}, \mathrm{AD}$, and $\mathrm{RD}$ in the postcentral gyrus remained associated with executive functioning; and $\mathrm{MD}, \mathrm{AD}$, and $\mathrm{RD}$ in the hippocampus remained associated with memory. These findings might be because microstructural damage to myelin/axons/neurons ${ }^{37}$ (undetectable on conventional MR imaging) may lead to disruption of neuronal circuits. These microstructural changes are thought to be secondary to SVD and related to vascular risk factors, in particular to hypertension. ${ }^{38}$ Executive function is known to be the cognitive domain most sensitive to subtle and diffuse deterioration of microstructural integrity of vascular origin. ${ }^{9,39}$

To investigate to what extent hypertension contributed to our findings, we included blood pressure as an additional covariate in model 1, which did not affect any of the associations. This finding suggests that hypertension is an unlikely etiology for DTI abnormalities and cognitive dysfunction in our population. However, these findings should be interpreted with caution because only participants with a blood pressure of $\leq 160 \mathrm{~mm} \mathrm{Hg}$ were included, and all participants used antihypertensive treatment, following the strict inclusion criteria from the DANTE study.

Compared with diffusivity measures, FA had a weaker association with brain volume. The disparity in associations suggests that the DTI measures may reflect a different pathophysiology. FA reflects a normalized ratio of diffusion directionality, whereas MD reflects the overall magnitude of water diffusion. Although research on the underlying pathologic substrate is scarce, a lower FA is thought to reflect irreversible structural damage, such as loss of myelin/axons, whereas increased MD may indicate an increase in interstitial or extracellular fluid. ${ }^{40}$

The present results should be interpreted with caution because no causal inference can be made due to the cross-sectional design. Moreover, due to the strict selection criteria of the DANTE trial, the findings are only generalizable to older individuals using antihypertensive treatment without a history of serious cardiovascular disease or dementia. Finally, we performed multiple testing, which can increase the chance of type I errors (wrongfully rejecting the null hypothesis). The Bonferroni correction was not applied because this method is considered too conservative to use in multiple comparisons with outcomes that are correlated.

The strengths of the study include the extensive assessment of cognitive function and of microstructural integrity by using $\mathrm{FA}, \mathrm{MD}, \mathrm{AD}$, and $\mathrm{RD}$ in both white and gray matter. Moreover, in the analyses of the relationship between microstructural integrity and cognitive function, we are the first to adjust for all features of SVD, including the presence of cerebral microbleeds, to our knowledge.

\section{CONCLUSIONS}

DTI measures in white and gray matter were associated with worse functioning on several cognitive domains. Associations were independent of WMHs, lacunar infarcts, and cerebral microbleeds but strongly attenuated after adjusting for brain volume. Only white and gray matter fractional anisotropy and gray matter radial diffusivity were associated with executive functioning, irrespective of brain volume. Our findings indicate that the relationship between DTI abnormalities and cognitive function is largely explained by brain volume. 


\section{ACKNOWLEDGMENTS}

The authors thank all the DANTE participants and the coinvestigators.

Disclosures: Justine E.F. Moonen—RELATED: Grant: Netherlands Organization for Health Research and Development (ZonMW), ${ }^{*}$ Comments: program Priority Medicines for the Elderly, No. 40-41600-98-9014. The funding organization played no role in the design, conduct, or analysis of the study. Wouter de Ruijter-RELATED: Grant: Netherlands Organization for Health Research and Development (ZonMW), ${ }^{*}$ Comments: reference No. 11-31010-03 (ZonMW acts on behalf of the Dutch Ministry of Health, Welfare and Sports). A.J.M. de Craen—RELATED: Grant: Netherlands Organization for Health Research and Development (ZonMW).* *Money paid to the institution.

\section{REFERENCES}

1. Wardlaw JM, Smith EE, Biessels GJ, et al; STandards for ReportIng Vascular changes on nEuroimaging (STRIVE v1). Neuroimaging standards for research into small vessel disease and its contribution to ageing and neurodegeneration. Lancet Neurol 2013;12:822-38 CrossRef Medline

2. Vernooij MW, Ikram MA, Tanghe HL, et al. Incidental findings on brain MRI in the general population. $N$ Engl J Med 2007;357: 1821-28 CrossRef Medline

3. Pantoni L. Cerebral small vessel disease: from pathogenesis and clinical characteristics to therapeutic challenges. Lancet Neurol 2010;9:689-701 CrossRef Medline

4. Thomas AJ, O'Brien JT, Davis S, et al. Ischemic basis for deep white matter hyperintensities in major depression: a neuropathological study. Arch Gen Psychiatry 2002;59:785-92 CrossRef Medline

5. Akoudad S, de Groot M, Koudstaal PJ, et al. Cerebral microbleeds are related to loss of white matter structural integrity. Neurology 2013;81:1930-37 CrossRef Medline

6. Reijmer YD, Freeze WM, Leemans A, et al. The effect of lacunar infarcts on white matter tract integrity. Stroke 2013;44:2019-21 CrossRef Medline

7. Ropele S, Seewann A, Gouw AA, et al; LADIS study group. Quantitation of brain tissue changes associated with white matter hyperintensities by diffusion-weighted and magnetization transfer imaging: the LADIS (Leukoaraiosis and Disability in the Elderly) study. J Magn Reson Imaging 2009;29:268-74 CrossRef Medline

8. Schmierer K, Wheeler-Kingshott CA, Boulby PA, et al. Diffusion tensor imaging of post mortem multiple sclerosis brain. Neuroimage 2007;35:467-77 CrossRef Medline

9. Nitkunan A, Barrick TR, Charlton RA, et al. Multimodal MRI in cerebral small vessel disease: its relationship with cognition and sensitivity to change over time. Stroke 2008;39:1999-2005 CrossRef Medline

10. Tuladhar AM, van Norden AG, de Laat KF, et al. White matter integrity in small vessel disease is related to cognition. Neuroimage Clin 2015;7:518-24 CrossRef Medline

11. van Norden AG, de Laat KF, van Dijk EJ, et al. Diffusion tensor imaging and cognition in cerebral small vessel disease: the RUN DMC study. Biochim Biophys Acta 2012;1822:401-07 CrossRef Medline

12. Vernooij MW, Ikram MA, Vrooman HA, et al. White matter microstructural integrity and cognitive function in a general elderly population. Arch Gen Psychiatry 2009;66:545-53 CrossRef Medline

13. Jokinen H, Schmidt R, Ropele S, et al; LADIS Study Group. Diffusion changes predict cognitive and functional outcome: the LADIS study. Ann Neurol 2013;73:576-83 CrossRef Medline

14. Shimony JS, Sheline YI, D'Angelo G, et al. Diffuse microstructural abnormalities of normal-appearing white matter in late life depression: a diffusion tensor imaging study. Biol Psychiatry 2009; 66:245-52 CrossRef Medline

15. Moonen JE, Foster-Dingley JC, de Ruijter W, et al. Effect of Discontinuation of Antihypertensive Treatment in Elderly People on Cognitive Functioning: the DANTE Study Leiden-a randomized clin- ical trial. JAMA Intern Med 2015;175:1622-30 CrossRef Medline Medline

16. Behrens TE, Woolrich MW, Jenkinson M, et al. Characterization and propagation of uncertainty in diffusion-weighted MR imaging. Magn Reson Med 2003;50:1077-88 CrossRef Medline

17. Smith SM. Fast robust automated brain extraction. Hum Brain Mapp 2002;17:143-55 CrossRef Medline

18. Zhang Y, Brady M, Smith S. Segmentation of brain MR images through a hidden Markov random field model and the expectationmaximization algorithm. IEEE Trans Med Imaging 2001;20:45-57 CrossRef Medline

19. Foster-Dingley JC, Moonen JE, van den Berg-Huijsmans AA, et al. Lower blood pressure and gray matter integrity loss in older persons. J Clin Hypertens (Greenwich) 2015;17:630-37 CrossRef Medline

20. Foster-Dingley JC, van der Grond J, Moonen JE, et al. Lower blood pressure is associated with smaller subcortical brain volumes in older persons. Am J Hypertens 2015;28:1127-33 CrossRef Medline

21. Folstein MF, Folstein SE, McHugh PR. "Mini-mental state": a practical method for grading the cognitive state of patients for the clinician. J Psychiatr Res 1975;12:189-98 CrossRef Medline

22. Houx PJ, Jolles J, Vreeling FW. Stroop interference: aging effects assessed with the Stroop Color-Word Test. Exp Aging Res 1993;19: 209-24 CrossRef Medline

23. Arbuthnott K, Frank J. Trail making test, part B as a measure of executive control: validation using a set-switching paradigm. J Clin Exp Neuropsychol 2000;22:518-28 CrossRef Medline

24. Lezak MD, Howieson DB, Loring DW. Neuropsychological Assessment. 4th ed. New York: Oxford University Press; 2004

25. Van der Elst W, van Boxtel MP, Van Breukelen GJ, et al. The Letter Digit Substitution Test: normative data for 1,858 healthy participants aged 24-81 from the Maastricht Aging Study (MAAS) - influence of age, education, and sex. J Clin Exp Neuropsychol 2006;28: 998-1009 CrossRef Medline

26. D'Ath $\mathrm{P}$, Katona $\mathrm{P}$, Mullan E, et al. Screening, detection and management of depression in elderly primary care attenders, I: the acceptability and performance of the 15 item Geriatric Depression Scale (GDS15) and the development of short versions. Fam Pract 1994;11:260-66 CrossRef Medline

27. Starkstein SE, Mayberg HS, Preziosi TJ, et al. Reliability, validity, and clinical correlates of apathy in Parkinson's disease. J Neuropsychiatry Clin Neurosci 1992;4:134-39 CrossRef Medline

28. Smith SM, Jenkinson M, Johansen-Berg H, et al. Tract-based spatial statistics: voxelwise analysis of multi-subject diffusion data. Neuroimage 2006;31:1487-505 CrossRef Medline

29. Wessa M, King AV, Meyer P, et al. Impaired and preserved aspects of feedback learning in aMCI: contributions of structural connectivity. Brain Struct Funct 2016;221:2831-46 CrossRef Medline

30. Brueggen K, Dyrba M, Barkhof F, et al. Basal forebrain and hippocampus as predictors of conversion to Alzheimer's disease in patients with mild cognitive impairment: a multicenter DTI and volumetry study. J Alzheimers Dis 2015;48:197-204 CrossRef Medline

31. Reginold W, Itorralba J, Tam A, et al. Correlating quantitative tractography at 3T MRI and cognitive tests in healthy older adults. Brain Imaging Behav 2015 Dec 9. [Epub ahead of print] CrossRef Medline

32. de Jong LW, van der Hiele K, Veer IM, et al. Strongly reduced volumes of putamen and thalamus in Alzheimer's disease: an MRI study. Brain 2008;131:3277-85 CrossRef Medline

33. Wang $\mathrm{Z}$, Wang $\mathrm{J}$, Zhang $\mathrm{H}$, et al. Interhemispheric functional and structural disconnection in Alzheimer's disease: a combined resting-state fMRI and DTI study. PLoS One 2015;10:e126310 CrossRef Medline

34. Ota M, Sato N, Nakata Y, et al. Relationship between apathy and diffusion tensor imaging metrics of the brain in Alzheimer's disease. Int J Geriatr Psychiatry 2012;27:722-26 CrossRef Medline

35. Reppermund $S$, Zhuang L, Wen W, et al. White matter integrity and late-life depression in community-dwelling individuals: diffusion 
tensor imaging study using tract-based spatial statistics. BrJ Psychiatry 2014;205:315-20 CrossRef Medline

36. Ly M, Canu E, Xu G, et al. Midlife measurements of white matter microstructure predict subsequent regional white matter atrophy in healthy adults. Hum Brain Mapp 2014;35:2044-54 CrossRef Medline

37. Peters A. The effects of normal aging on myelin and nerve fibers: a review. J Neurocytol 2002;31:581-93 CrossRef Medline

38. Muñoz Maniega S, Chappell FM, Valdés Hernández MC, et al. Integrity of normal-appearing white matter: influence of age, visible le- sion burden and hypertension in patients with small-vessel disease. J Cereb Blood Flow Metab 2016 Mar 1. [Epub ahead of print] CrossRef Medline

39. O'Sullivan M, Morris RG, Huckstep B, et al. Diffusion tensor MRI correlates with executive dysfunction in patients with ischaemic leukoaraiosis. J Neurol Neurosurg Psychiatry 2004;75:441-47 CrossRef Medline

40. Kale RA, Gupta RK, Saraswat VA, et al. Demonstration of interstitial cerebral edema with diffusion tensor $\mathrm{MR}$ imaging in type $\mathrm{C}$ hepatic encephalopathy. Hepatology 2006;43:698-706 CrossRef Medline 